\title{
Disturbed striatoprefrontal mediated visual behaviour in moderate to severe parkinsonian patients
}

\author{
L Crevits, K De Ridder
}

\begin{abstract}
Objectives-To study visuospatial and visual memory functions in moderate to severe parkinsonian patients.

Methods-Visual antisaccades (AS) and remembered saccades (RS) were examined in 30 patients with moderate to severe Parkinson's disease and in 44 age matched controls. AS are saccades in the direction opposite to the target. RS are saccades towards the remembered position of a target that is no longer visible.

Results-Patients with Parkinson's disease had serious difficulties in suppressing a reflex saccade ("visual grasping") or they made no saccade at all ("visual akinesia"). The remembered saccade was often wrongly directed.

Conclusions-These types of errors point to a dysfunction in the striatoprefrontal loop. The discrepancy of the results with those in the literature, which are mostly normal, could be explained by the more advanced stage of our patients. This might correspond to the development of unresponsiveness to levodopa or of nondopaminergic lesions.
\end{abstract}

(F Neurol Neurosurg Psychiatry 1997;63:296-299)

Keywords: antisaccade; remembered saccade; Parkinson's disease; striatoprefrontal circuitry

The analysis of voluntary eye movements as a result of complex cognitive or memory tasks, such as antisaccades and remembered saccades, has assumed an important role in assessing higher cortical function. ${ }^{1}$ Visual antisaccades are fast eye movements made in the direction opposite to a peripherally appearing visual target. Visually remembered saccades are saccades made towards the position of a target that has been perceived a moment before. Both types of saccades are volitional saccades, internally triggered with a goal. ${ }^{2}$

In the literature, only small groups of mild parkinsonian patients have been studied. We studied visual antisaccades (AS) and visually remembered saccades (RS) in 30 patients with moderate to severe Parkinson's disease (PD) to evaluate more complex visual behaviour.

\section{Patients and methods}

SUBJECTS

Patients with idiopathic Parkinson's disease (stage III-IV of Hoehn and Yahr) ${ }^{3}$ and controls were classified into two groups according to their age (44 to 64 years and $\geqslant 65$ years). A comparison was made between the younger patients and the younger controls ( $\mathrm{Yp} v \mathrm{Yc}$ ) and between the older patients and the older controls (Op $v$ Oc). The diagnosis of idiopathic Parkinson's disease was based on clinical history, neurological examination, and initial response to levodopa. ${ }^{4}$ The procedure was approved by the ethics commision and all subjects gave informed consent.

\section{Patients}

Group Yp consisted of 10 persons (five men, five women, mean age: 56 years, range 47-63 years). Group Op consisted of 20 patients (six men, 14 women, mean age: 73 years, range: 66-82 years). All patients were receiving their normal antiparkinsonian therapy at the time of testing: levodopa (Yp eight patients; Op 20 patients), pergolide (Yp one; Op two), bromocryptine ( $\mathrm{Yp}$ three; Op eight), selegiline ( $\mathrm{Yp}$ one; Op five), anticholinergic drugs (Yp three; Op two), clozapine (Yp three; Op three), amantadine (Yp one; Op one). Withdrawal of these medications was thought not to be justified ethically. There was no clinical evidence of dementia according to DSM-IV criteria or other neurological diseases in any of the patients.

\section{Controls}

Forty four people without neurological disorders were studied with the same paradigms as the patients. Group Yc consisted of 19 controls (nine men, 10 women, mean age 53 years, range 44-63 years). Group Oc consisted of 25 normal healthy subjects ( 11 men, 14 women, mean age 72 years, range $66-84$ years).

Patients and controls were not taking any medication known to affect oculomotor or cerebral functions, except for the antiparkinsonian therapy.

Some subjects were excluded from the study, because either their tremor interfered too excessively with the registration or they were not able to perform the requested tasks. In the antisaccade paradigm one subject of group Oc, one patient of group $\mathrm{Yp}$, and seven patients of group Op could not perform the task. In the remembered saccade paradigm one subject of group Oc, one patient of group Yp, and 10 patients of group Op were excluded.

METHODS

Horizontal eye movements were recorded by electro-oculography: two electrodes were fixed 
at the outer canthus of each eye. Blinking was simultaneously detected by electrodes above and below the right eye. The bandwidth of the AC amplifier was from 0.016 to $15 \mathrm{~Hz}$ (this is not critical because metrics were not studied). All recordings were performed in semidarkness. Subjects were seated in a chair at $1 \mathrm{~m}$ distance from a screen with three light emitting diode targets (LEDs). Head position was maintained by asking them to keep the head motionless. Changing LEDs happened every two to four seconds. There were never two LEDs illuminated at the same time. Each recording session lasted about 15 minutes. Before recording the antisaccade test, subjects practised until they understood the tasks; the same was done for the remembered saccade test. Each antisaccade test and each remembered saccade test consisted of 25 stimuli to the right and as many to the left in a random sequence. The type and the number of errors of the saccades were evaluated, starting with the antisaccade or the remembered saccade task alternated to avoid an effect of order. There was a break of five minutes between the antisaccade and the remembered saccade task to minimise the risk of perseveration.

\section{Antisaccade}

A central LED was illuminated at the beginning of each trial. The subject fixed this central target. After two to four seconds a lateral target $\left(20^{\circ}\right)$ switched on, the central flash switched off simultaneously, and the subject had to look in the opposite direction (fig 1 ).

\section{Centre off remembered saccade}

The subject was fixating a central LED, illuminated at the start of each trial. Then a lateral target $\left(20^{\circ}\right)$ switched on for two to four seconds and the central LED switched off while the subject remained looking at the central position. As soon as the central LED was illuminated again (and the lateral spot switched off), the subject had to make a saccade to the remembered position of the target as quickly as possible. A command "to the middle" was followed by return to the central point (fig 2).

STATISTICS

Comparison of the results of the antisaccade and remembered saccade between the patients with Parkinson's disease and the controls were studied with the Mann-Whitney $U$ test. For a cross correlation of the errors between the AS test and the RS test Spearman's correlation coefficients were calculated.

\section{Results}

Error rates were calculated in percentages. Errors to the left and to the right were taken together. Antisaccades and remembered saccades which were impossible to evaluate because of blinking, sweat potentials, or tremors interfering with the registration of the eye movements, were excluded. In each group more than $97.8 \%$ of the antisaccades and remembered saccades were analysed, except in the group Op, where $89.2 \%$ of the remembered

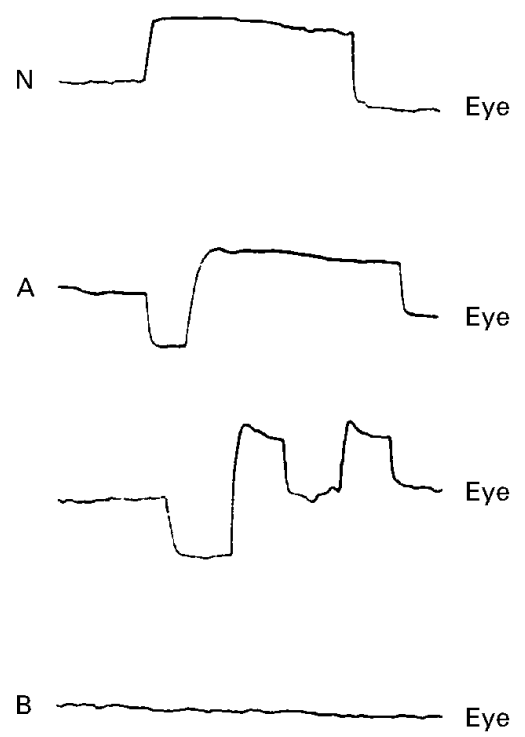

C

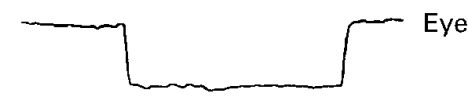

Right $\left(20^{\circ}\right)$

EIIA

WIIIIA Target Middle

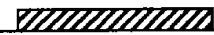

Left $\left(20^{\circ}\right)$

Figure 1 Electro-oculography and schematic representation of the $A S$ paradigm. $N=$ normal $A S$, $A=$ error $A ; B=$ error $B ; C=$ error $C$. An upward deflection in the EOG means an eye movement to the right.

saccades were taken into account. The errors were spread across the subjects. Tables 1 and 2 summarise the results of the AS and RS tests respectively.

\section{ANTISACCADE}

Three kind of errors occurred in the AS paradigm (fig 1). Error A: the subject could not suppress the reflex to look at the target (distractibility) but he made a correction; error B: the subject did not perform a saccade at all (no eye movements); error C: the subject remained looking in the wrong direction. Patients with Parkinson's disease had significantly more difficulties in suppressing a reflex saccade (error A) than controls ( $\mathrm{P}=0.028$ (Yc $v$ $\mathrm{Yp}) ; \mathrm{P}=0.003(\mathrm{Oc} v \mathrm{Op})$ ). No reaction at all (error B) achieved significance at the $\mathrm{P}=0.040$ level in the younger and at the $\mathrm{P}<0.001$ level in the older subjects. There was no difference for error $\mathrm{C}$ between patients and controls. 
Table 1 Results of the antisaccade test

\begin{tabular}{lrccc}
\hline & $\begin{array}{l}\text { Controls } \\
\text { 44-64 } y(Y c)\end{array}$ & $\geqslant 65 y(\mathrm{Oc})$ & $\begin{array}{l}\text { Patients } \\
\text { 44-64 } y\left(Y_{p}\right)\end{array}$ & $\geqslant 65 y(\mathrm{O} p)$ \\
\hline $\mathrm{E}(\mathrm{A})$ & $11.74(9.90)$ & $16.48(38.00)$ & $25.43(38.00)^{\star}$ & $39.57(63.91)^{\star}$ \\
$\mathrm{E}(\mathrm{B})$ & $0.21(4.00)$ & $0(-)$ & $3.36(12.24)^{\star}$ & $4.18(31.20)^{\star \star}$ \\
$\mathrm{E}(\mathrm{C})$ & $0.32(2.00)$ & $1.10(6.00)$ & $1.34(10.00)$ & $5.61(32.00)$ \\
\hline
\end{tabular}

$\star \mathrm{P}<0.005 ;{ }^{\star \star} \mathrm{P}<0.001$ patients $v$ controls.

Values are mean error percentage (range). $\mathrm{E}(\mathrm{A})=$ error $\mathrm{A} ; \mathrm{E}(\mathrm{B})=$ error $\mathrm{B} ; \mathrm{E}(\mathrm{C})=$ error $\mathrm{C}$. $\mathrm{Y}=$ young; $\mathrm{O}=$ old .

Table 2 Results of the remembered saccade test

\begin{tabular}{|c|c|c|c|c|}
\hline & $\begin{array}{l}\text { Controls } \\
44-64 y(Y c)\end{array}$ & $\geqslant 65 y(O c)$ & $\begin{array}{l}\text { Patients } \\
44-64 \text { y }(Y p)\end{array}$ & $\geqslant 65 y(O p)$ \\
\hline$\overline{E(A)}$ & $11.69(38.00)$ & $21.58(54.00)$ & $30.43(51.32)^{\star}$ & $35.93(81.74)$ \\
\hline E (B) & $0.42(2.04)$ & $0.68(4.00)$ & $0.46(2.13)$ & $1.69(8.82)$ \\
\hline $\mathrm{E}(\mathrm{C})$ & $2.32(14.00)$ & $1.20(4.00)$ & $9.20(33.33)$ & $15.45(43.58)^{\star \star}$ \\
\hline $\mathrm{E}(\mathrm{D})$ & $0.00(-)$ & $0.36(6.00)$ & $0.23(2.00)$ & $0.20(2.00)$ \\
\hline $\mathrm{E}(\mathrm{E})$ & $0.00(-)$ & $0.08(2.00)$ & $0.00(-)$ & $0.00(-)$ \\
\hline$E(F)$ & $0.00(-)$ & $0.36(4.00)$ & $0.70(4.25)^{\star}$ & $2.45(10.00)^{\star}$ \\
\hline $\mathrm{E}(\mathrm{D}, \mathrm{E}, \mathrm{F})$ & $0.00(-)$ & $0.08(6.00)$ & $0.94(4.25)^{\star}$ & $2.65(10.00)^{\star}$ \\
\hline $\mathrm{E}(\mathrm{E}, \mathrm{F})$ & $0.00(-)$ & $0.44(4.00)$ & $0.70(4.25)^{\star}$ & $2.45(10.00)^{\star}$ \\
\hline $\mathrm{N}+\mathrm{E}(\mathrm{D})$ & $95.47(20.00)$ & $89.89(44.00)$ & $82.44(38.00)^{\star}$ & $67.60(80.00)^{\star}$ \\
\hline
\end{tabular}

$\star \mathrm{P}<0.05 ;{ }^{\star \star} \mathrm{P}<0.001$ patients $v$ controls.

Values are mean error percentage (range). $\mathrm{E}(\mathrm{A})=$ error $\mathrm{A} ; \mathrm{E}(\mathrm{B})=$ error $\mathrm{B} ; \mathrm{E}(\mathrm{C})=$ error $\mathrm{C}$; $\mathrm{E}(\mathrm{D})=$ error $\mathrm{D} ; \mathrm{E}(\mathrm{E})=$ error $\mathrm{E} ; \mathrm{E}(\mathrm{F})=$ error $\mathrm{F} ; \mathrm{E}(\mathrm{D}, \mathrm{E}, \mathrm{F})=$ error $\mathrm{D}+$ error $\mathrm{E}+$ error $\mathrm{F} ; \mathrm{E}(\mathrm{E}, \mathrm{F})=$ error $\mathrm{E}+\operatorname{error} \mathrm{F} ; \mathrm{N}+\mathrm{E}(\mathrm{D})=$ Normal $\mathrm{RS}+$ error $\mathrm{D}$.

CENTRE OFF REMEMBERED SACCADE

The RS was divided in two parts: a possible premature reaction and the "real" remembered saccade. In a normal RS paradigm, the subject had to remain looking at the central point instead of looking to the peripheral appearing visual target. Whenever a subject performed a saccade too soon, it was called a premature reaction. Two variants of a premature reaction were distinguished (fig 2): firstly, (error A) the subject was looking at the target and secondly (error B) the subject was looking at the opposite side. In the "real" remembered

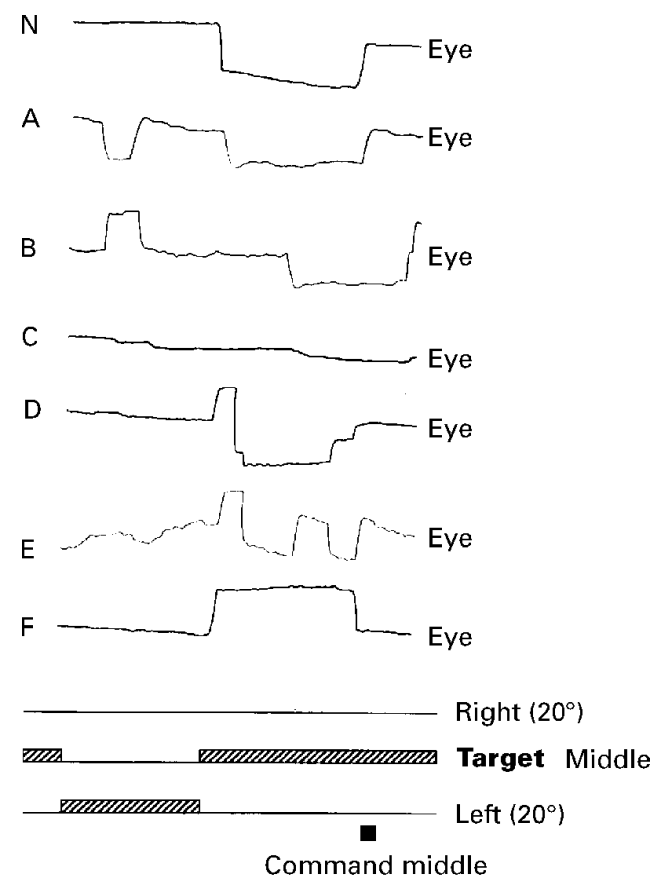

Figure 2 Electro-oculography and schematic representation of the $R S$ paradigm. $N=$ normal $R S ; A=$ error $A ; B=$ error $B ; C=$ error $C ; D=$ error $D ; E=$ error $E ; F=$ error F. An upward deflection in the EOG means an eye movement to the right. saccade four kinds of errors occurred. Error C: the subject did not perform a saccade at all; error D: the subject was looking in the wrong direction but he made a stable correction; error $\mathrm{E}$ : the subject was looking in the wrong direction, he made a correction that was followed by to and fro saccades with varying intersaccadic interval (unstable correction); error F: the subject was looking in the wrong direction and remained wrong. Young patients with Parkinson's disease had more difficulties in suppressing a reflex toward the target (error A) than young controls $(P=0.020)$. An almost significant difference was achieved between group $\mathrm{Op}$ and group $\mathrm{Oc}(\mathrm{P}=0.07)$. Patients with Parkinson's disease did not show a significant difference in their error B rates compared with controls.

No reaction at all (error C) occurred almost significantly more in younger patients than in controls $(P=0.07)$. This difference became very significant, however, between the older patients and the older controls $(\mathrm{P}<0.001)$. Looking in the wrong direction (error $\mathrm{D}+\mathrm{E}+\mathrm{F}$ ) was significantly higher in patients than in controls $(\mathrm{P}=0.030(\mathrm{Yc} v \mathrm{Yp}) ; \mathrm{P}=0.020(\mathrm{Oc} v \mathrm{Op}))$. Error D and error $\mathrm{E}$ showed no difference between patients and controls. There was a significant difference for error $\mathrm{F}$ between patients and controls, both in the younger $(\mathrm{P}=0.025)$ and in the older groups $(\mathrm{P}=0.036)$. Patients with Parkinson's disease showed a significant difference in their error $\mathrm{E}+\mathrm{F}$ rate than controls ( $\mathrm{P}=0.050$ (Yc $v \mathrm{Yp}$ ); $\mathrm{P}=0.036$ (Oc $v$ Op)). The total number of primary correct RS (n) plus corrected RS (error D) was significantly higher in controls than in patients $(\mathrm{P}=0.003$ ( $\mathrm{Yc} v \mathrm{Yp}) ; \mathrm{P}=0.002(\mathrm{Oc} v \mathrm{Op})$ ). Table 3 shows the correlation of the errors across the AS test and the RS test.

\section{Discussion}

In previous studies, no significant alterations of AS in Parkinson's disease have been reported. $^{5-7}$ Our patients with Parkinson's disease, on the contrary, made more errors than age matched controls-for example, they could not suppress a reflexive saccade to the target (error A and error C in the AS test, error A in the RS test). This "visual grasp reaction" is known to occur in prefrontal lesions. ${ }^{8}$ Even in a larger amount of AS trials, no saccade at all was generated. We call this phenomenon "visual akinesia" (error B in the AS test, error $\mathrm{C}$ in the RS test).

The preliminary requirement for RS is to suppress a reflex saccade. The patients with Parkinson's disease reacted more prematurely than controls by "visual grasping". The cross

Table 3 Cross correlation of errors

\begin{tabular}{|c|c|}
\hline$A S$ test $-R S$ test & $A S$ test $-R S$ test \\
\hline $\begin{array}{l}\mathrm{E}(\mathrm{A})+\mathrm{E}(\mathrm{C})-\mathrm{E}(\mathrm{A}) \\
\text { "grasping" }\end{array}$ & $\begin{array}{l}\mathrm{E}(\mathrm{B})-\mathrm{E}(\mathrm{C}) \\
\text { "akinesia" }\end{array}$ \\
\hline $\begin{array}{l}\text { Controls } r=0.7^{\star \star \star} \\
\text { Patients } r=0.6^{\star \star}\end{array}$ & $\begin{array}{l}\mathrm{r}=0.07 \\
\mathrm{r}=0.4^{\star}\end{array}$ \\
\hline
\end{tabular}

$\star \mathrm{P}=0.07 ;{ }^{\star \star} \mathrm{P}<0.005 ;{ }^{\star \star \star} \mathrm{P}<0.001$

$\mathrm{E}(\mathrm{A})=$ error $\mathrm{A} ; \mathrm{E}(\mathrm{B})=$ error $\mathrm{B} ; \mathrm{E}(\mathrm{C})=$ error $\mathrm{C} ; \mathrm{R}=$ correlation coefficient. 
correlation of these reflexive errors between the two tasks was very significant (table 3 ). In an important number of patients with Parkinson's disease, the RS was in the wrong direction, or "visual akinesia" was present especially in the older group. Wrongly directed RS and visual akinesia are not mentioned in the literature..$^{9-13}$ As the final eye position in the RS test was ambiguous or in the wrong direction (error $\mathrm{E}+\mathrm{F}$ ), a dysfunction of visuospatial behaviour is convincing.

The mistakes in the AS and RS can be summarised as reflexive visual grasping, visual akinesia, and wrong direction RS. These reactions can be ascribed to a frontal dysfunction. In particular, disturbed suppression of reflexive saccades, and disturbed visuospatial memory can be caused by a dorsolateral prefrontal dysfunction (area 46). ${ }^{2}$ Although a recent PET study questioned the role of the dorsolateral prefrontal area in the control of saccades in humans,${ }^{14}$ this area is known to receive a dopaminergic input that is failing in Parkinson's disease. Furthermore, experiments in monkeys have shown that dopamine antagonists locally applied to the dorsolateral prefrontal cortex interfere with visually remembered saccades. ${ }^{1516}$

Visual akinesia is a prominent feature in the older patients, as well in the AS as in the RS test. It is not clear whether this can be ascribed to a frontal deficit or to a lack of motor initiation. Although none of the subjects was demented, subtle attention deficits cannot be excluded as formal neuropsychological examination is lacking.

As there is hardly any indication that the frontal cortex is structurally damaged, we attribute the disturbances of the AS and the RS in Parkinson's disease to a dysfunction in the striatoprefrontal circuitry. Our results for AS and RS do not agree with those in the literature. This could hardly have been explained by slightly different testing paradigms. Anticholinergic drugs can be incriminated in frontal cognitive dysfunction ${ }^{17}$ and can cause an increased error rate of AS in Parkinson's disease. ${ }^{18}$ However, only four of our patients were on anticholinergic medication and all these patients did understand the tasks. In most cases antisaccade errors were rapidly and spontaneously corrected (error A) instead of remaining wrong (error $\mathrm{C}$ ); this indicates that the subjects understood the tasks. So, the higher error rates in Parkinson's disease did not reflect poor patient motivation.

Although the larger number of patients in our study may not be ignored, we think the more impaired condition of the present patients (stage III-IV) accounts for the disagreement with the literature. It could be that the structures mediating visuospatial oculomotor behaviour have become unresponsive to levodopa. Finally, the dysfunctions found in our study might correspond to the development of non-dopaminergic lesions and these have been reported postmortem. ${ }^{19}$

1 Currie J, Ramsden B, Mc Arthur C, Maruff P, Validation of a clinical antisaccadic eye movement test in the assessment of dementia. Arch Neurol 1991;48:644-8.

2 Pierrot-Deseilligny C. Saccade and smooth-pursuit impairment after cerebral hemispheric lesions. Eur Neurol 1994;34:121-34.

3 Hoehn MM, Yahr MD. Parkinsonism: onset, progression and mortality. Neurology 1967;17:427-42.

4 Hughes AJ, Daniel SE, Kilford L, Lees AJ. Accuracy of clinical diagnosis of idiopathic Parkinson's disease: a clinico-pathological study of 100 cases. $\mathcal{F}$ Neurol Neurosurg Psychiatry 1992;55:181-4.

5 Lueck CJ, Tanyeri S, Crawford TJ, Henderson L, Kennard C. Antisaccades and remembered saccades in Parkinson's disease. F Neurol Neurosurg Psychiatry 1990;53:284-8.

6 Vidailhet M, Rivaud S, Gouider-Khouja N, Pillon B, Bonnet AM, Gaymard B, et al. Eye movements in Parkinsonian syndromes. Ann Neurol 1994;35:420-6.

7 Fukushima J, Fukushima K, Miyasaka K, Yamashita I. Voluntary control of saccadic eye movement in patients with frontal cortical lesions and parkinsonian patients in comparison with that in schizophrenics. Biol Psychiatry 1994;36:21-30.

8 Guitton D, Buchtel HA, Douglag RM. Frontal lobe lesions in man cause difficulties in suppressing reflexive glances and in generating goal-directed saccades. Exp Brain Res 1985; 58:455-72.

9 Crawford TJ, Henderson L, Kennard C. Abnormalities of nonvisually guided eye movements in Parkinson's disease. Brain 1989;112:1573-86.

10 Lueck CJ, Crawford TJ, Henderson L, Van Gisbergen JAM, Duysens J, Kennard C. Saccadic eye movements in Parkinson's disease: II. Remembered saccades-towards a unified hypothesis? $Q \mathcal{F}$ Exp Psychol A 1992;45:211-33.

11 Nakamura T, Bronstein AM, Lueck C, Marsden CD, Rudge $P$. Vestibular, cervical and visual remembered saccades in Parkinson's disease. Brain 1994;117:1423-32.

12 Shaunak S, O'Sullivan E, Crawford T, Lawden M, Blunt S, Henderson L, Kennard C. Remembered saccades with variable delay in Parkinson's disease. F Neurol 1994;241: S149-50.

13 Vermersch AI, Rivaud S, Vidailhet M, Bonnet AM, Gaymard B, Agid Y, Pierrot-Deseilligny C. Sequences of memory-guided saccades in Parkinson's disease. Ann Neurol 1994;35:487-90.

14 Anderson TJ, Jenkins IH, Brooks DJ, Hawken MB, Frackowiak RSJ, Kennard C. Cortical control of saccades and fixation in man. A PET study. Brain 1994;117:107384 .

15 Sawaguchi T, Goldman-Rakic PS. D1-dopamine receptors in prefrontal cortex: involvement in working memory. Science 1991;251:947-59.

16 Sawaguchi T, Goldman-Rakic PS. The role of D1dopamine receptor in working memory: local injections of dopamine antagonists into the prefrontal cortex of rhesus monkeys performing an oculomotor delayed response task. monkeys performing an oculom

f Neurophysiol 1994;71:515-28.
17 Dubois B, Pillon B, Lhermitte F, Agid Y. Anticholinergic deficiency and frontal dysfunction in Parkinson's disease. Ann Neurol 1990;28:117-21.

18 Kitagawa M, Fukushima J, Tashiro K. Relationship between antisaccades and the clinical symptoms in Parkinson's disease. Neurology 1994;44:2285-9.

19 Dubois B, Pillon B. Biochemical correlates of cognitive changes and dementia in Parkinson's disease. In: Huber SJ, Cummings JL, eds. Parkinson's disease: neurobehavioral aspects. Oxford: Oxford University Press, 1992. 